\title{
OS OBJETIVOS DA EDUCAÇÃO SUPERIOR E O ENSINO A PARTIR DE SITUAÇÕES-PROBLEMA
}

\section{THE OBJECTIVES OF HIGHER EDUCATION AND TEACHING FROM PROBLEM SITUATIONS}

\section{LOS OBJETIVOS DE LA EDUCACIÓN SUPERIOR Y LA ENSEÑANZA DE SITUACIONES DE PROBLEMAS}

\author{
Fernando Frederico de Almeida Júnior \\ Pós-doutor em Direitos Humanos pela Universidade de Salamanca (Espanha) \\ Pós-doutor em Direito pela Università degli Studi di Messina (Itália) \\ Pós-doutor em Direito pela Universidade de Coimbra (Portugal) \\ Doutor em Educação pela Universidade Federal de São Carlos (Brasil) \\ Mestre em Direito pela Universidade de Ribeirão Preto (Brasil) \\ Professor em cursos de graduação e pós-graduação em Direito e Educação \\ E-mail: frederico.jau@gmail.com
}

\begin{abstract}
RESUMO
Investigar os objetivos do ensino superior e apresentar uma maneira de observá-los dentro de sala de aula consiste na temática central deste trabalho. Para tanto, discute-se os pilares da educação de acordo com o Relatório Delors, os saberes necessários à educação do futuro segundo Morin, a Declaração Mundial sobre Educação Superior no Século XXI e a Constituição Federal do Brasil. Além disso, discorre-se acerca da teoria e prática em sala de aula e sobre métodos e técnicas de ensino, com enfoque no método de problemas.
\end{abstract}

Palavras-chave: Educação superior. Objetivos. Metodologia de ensino.

\section{ABSTRACT}

Investigating the goals of higher education and presenting a way to observe them within the classroom is the central theme of this work. To this end, we discuss the pillars of education according to the Delors Report, the knowledge needed for future education according to Morin, the World Declaration on Higher Education in the 21st Century and the Federal Constitution of Brazil. In addition, it discusses the theory and practice in the classroom and about teaching methods and techniques, focusing on the problem method.

Keywords: Higher education. Goals. Teaching methodology.

\section{RESUMEN}

Investigar los objetivos de la educación superior y presentar una forma de observarlos dentro del aula es el tema central de este trabajo. Con este fin, discutimos los pilares de la educación según el Informe Delors, el conocimiento necesario para la educación futura según Morin, la Declaración Mundial sobre Educación Superior en el siglo XXI y la Constitución Federal de Brasil. Además, analiza la teoría y la práctica en el aula y sobre los métodos y técnicas de enseñanza, centrándose en el método del problema.

Palabras clave: Educación universitaria. Objetivos. Metodología de la enseñanza.

$$
\text { RELEDUC | ISE | v. } 3 \text { | n. } 1 \text { | dez. } 2020
$$




\section{INTRODUÇÃO}

Embora ainda hoje seja bastante comum nas salas de aula dos cursos superiores, já está ultrapassado o procedimento metodológico que privilegia apenas o ato de repetição e memorização do conteúdo ensinado.

É imperioso que o professor incentive no aluno a consciência crítica e uma das melhores maneiras de alcançá-la é fazendo com que o discente se depare com situações-problema reais e/ou simuladas, que exijam capacidade de interpretação, análise crítica e resposta conceitualmente fundamentada, trazendo a realidade para o ambiente da sala de aula e permitindo vinculação mais fácil da teoria com a prática. Oportuniza-se ao aluno aprender fazendo, instrumentalizar o conhecimento e construir o pensamento, criando nele a capacidade de autoaprendizagem e ensinando-o a ter autonomia nas aquisições científicas indispensáveis para seu êxito profissional futuro.

Destarte, o objetivo deste trabalho é apresentar um modo de atuar em sala de aula como professor de um curso superior, sem depender de mudanças curriculares, da política educacional do governo ou da própria instituição de ensino, mas sempre levando em conta os reais objetivos da educação superior.

Evidente que não se pretende nestas poucas palavras esgotar o assunto ou mesmo apresentar um método pronto e acabado de ministrar aulas e de trabalhar a teoria e a prática. Como já dito, almeja-se com estas linhas demonstrar, num conciso compêndio, apenas e tão somente uma das maneiras de agir numa sala de aula de um curso superior, não para servir de exemplo para outros colegas, pois isto significaria ousadia exagerada, mas sim para receber críticas, positivas e/ou negativas, assim como para iniciar e/ou dar continuidade à altercação.

Desse modo, averiguar quais são os objetivos do ensino superior e apresentar uma maneira de observá-los dentro de uma sala de aula consiste na temática central deste trabalho.

Para tanto, discutir-se-á, neste texto, os pilares da educação de acordo com o denominado Relatório Delors, os saberes necessários à educação do futuro segundo Edgar Morin, a Declaração Mundial sobre Educação Superior no Século XXI e a Constituição Federal do Brasil. Além disso, discorrer-se-á sobre teoria e prática em sala de aula e sobre métodos e técnicas de ensino, com enfoque no método de problemas e nas respectivas técnicas, apresentando inclusive alguns procedimentos paralelos a serem respeitados pelos docentes.

Acredita-se que a estrutura proposta possibilitará alcançar o que se pretende com este trabalho, sem a pretensão de uma abordagem completa e do esgotamento do assunto.

$$
\text { RELEDUC | ISE | v. } 3 \text { | n. } 1 \text { | dez. } 2020
$$




\section{OS OBJETIVOS DA EDUCAÇÃO SUPERIOR}

Discorrer sobre os objetivos do ensino superior é algo mais complexo do que se imagina, notadamente porque o escopo da educação superior não se limita às metas fixadas na legislação nacional ou por órgãos do Poder Público local, devendo ser almejados também os objetivos do ensino superior estabelecidos nos tratados, instrumentos e relatórios internacionais.

Desse modo, estudar a educação superior implica obrigatoriamente na verificação do que se defende a este respeito em nível mundial. É impossível e desaconselhável refletir sobre o destino particular de cada Estado-Nação ignorando o mesmo fenômeno objeto do estudo em escala global.

\subsection{Os pilares da educação: o Relatório Delors}

Nesta linha de pensamento, importa evidenciar, ab initio, o denominado Relatório Delors. A Conferência Geral da UNESCO, em novembro de 1991, convidou o diretor-geral "a convocar uma comissão internacional encarregada de refletir sobre educar e aprender para o século XXI". Federico Mayor pediu a Jacques Delors que presidisse tal comissão, que reuniu quatorze outras personalidades de todas as regiões do mundo, vindas de horizontes culturais e profissionais diversos. A Comissão Internacional sobre Educação para o Século XXI foi criada, oficialmente, no início de 1993. Financiada pela UNESCO, e servida por um secretariado posto à sua disposição por esta mesma organização, a Comissão pôde tirar partido dos preciosos recursos ao dispor da UNESCO e da sua experiência internacional, assim como de um impressionante acervo de informações, sem, contudo, deixar de conduzir os seus trabalhos e elaborar as suas recomendações com independência (DELORS, 1998, p. 268).

Os trabalhos da referida Comissão se encerraram em 1996, consignando-se no relatório que, ante os múltiplos desafios do futuro, a educação surge como um trunfo indispensável à humanidade na sua construção dos ideais da paz, da liberdade e da justiça social. A Comissão considerou as políticas educativas um processo permanente de enriquecimento dos conhecimentos, do saber-fazer, mas também e talvez em primeiro lugar, como uma via privilegiada de construção da própria pessoa, das relações entre indivíduos, grupos e nações. À educação cabe a missão de fazer com que todos, sem exceção, façam frutificar os seus talentos e 
potencialidades criativas, o que implica, por parte de cada um, a capacidade de se responsabilizar pela realização do seu projeto pessoal (DELORS, 1998, p. 11-16).

Impõe-se cada vez mais, segundo a Comissão, o conceito de educação ao longo de toda a vida, dadas as vantagens que oferece em matéria de flexibilidade, diversidade e acessibilidade no tempo e no espaço. É a ideia de educação permanente que deve ser repensada e ampliada. É que, além das necessárias adaptações relacionadas com as alterações da vida profissional, ela deve ser encarada como uma construção contínua da pessoa humana, dos seus saberes e aptidões, da sua capacidade de discernir e agir. Deve levar cada um a tomar consciência de si próprio e do meio ambiente que o rodeia, e a desempenhar o papel social que lhe cabe enquanto trabalhador e cidadão. É desejável que a escola transmita ainda mais o gosto e prazer de aprender, a capacidade de ainda mais aprender a aprender, a curiosidade intelectual (DELORS, 1998, p. 18).

Para a Comissão, a educação tem como objetivo essencial o desenvolvimento do ser humano na sua dimensão social. A política educativa deve ser suficientemente diversificada e concebida de modo a não se tornar um fator suplementar de exclusão social, sendo que a escola só pode ter êxito nesta tarefa se contribuir para a promoção e integração dos grupos minoritários, mobilizando os próprios interessados no respeito a sua personalidade (DELORS, 1998, passim).

Jacques Delors e seu grupo relataram que a educação, para poder dar resposta ao conjunto das suas missões, deve organizar-se em torno de quatro aprendizagens fundamentais que, ao longo de toda a vida, serão de algum modo para cada indivíduo os pilares do conhecimento.

O primeiro pilar da educação é o aprender a conhecer, que significa adquirir os instrumentos da compreensão. Como o conhecimento é múltiplo e evolui infinitamente, torna-se cada vez mais inútil tentar conhecer tudo. O processo de aprendizagem do conhecimento nunca está acabado e pode enriquecer-se com qualquer experiência. Outra coluna da educação refere-se ao aprender a fazer, para assim poder agir sobre o meio envolvente, objetivando adquirir não somente uma qualificação profissional, mas, de uma maneira mais ampla, competências que tornem a pessoa apta a enfrentar numerosas situações e a trabalhar em equipe, com reflexos também no âmbito das diversas experiências sociais ou de trabalho que se oferecem aos jovens e adolescentes. A terceira pilastra consiste no aprender a viver juntos, a fim de participar e cooperar com os outros em todas as atividades humanas, desenvolvendo a compreensão do outro e a percepção das interdependências, realizando projetos comuns e preparando-se para gerir conflitos, observando-se o respeito pelos valores do pluralismo, da compreensão mútua e da paz. Por fim, o aprender a ser, via essencial que integra as três precedentes, para melhor desenvolver RELEDUC | ISE | v. 3 | n. 1 | dez. 2020 
a personalidade e estar à altura de agir com cada vez maior capacidade de autonomia, de discernimento e de responsabilidade pessoal (DELORS, 1998, p. 89-102).

Tratando especificamente dos cursos superiores, o grupo chamou a atenção para o insucesso escolar e a necessidade de lutar contra ele. Asseverou-se que o insucesso atinge todas as categorias sociais, embora os jovens oriundos de meios desfavorecidos lhe sofram as consequências de uma maneira especial. São múltiplas as suas formas: sucessivas repetências, abandono durante os estudos, marginalização para cursos que não oferecem reais perspectivas e, no final das contas, abandono da escola sem qualificações nem competências reconhecidas. $\mathrm{O}$ insucesso escolar constitui, em qualquer dos casos, uma pecha profundamente inquietante no plano moral, humano e social; é, muitas vezes, gerador de situações de exclusão que marcam os jovens para toda a vida. O primeiro objetivo dos sistemas educativos deve ser reduzir a vulnerabilidade social dos jovens oriundos de meios marginais e desfavorecidos, a fim de romper o círculo vicioso da pobreza e da exclusão. As medidas a tomar passam pelo diagnóstico das dificuldades dos alunos mais novos, muitas vezes ligadas a sua situação familiar, e pela adoção de políticas de discriminação positiva em relação aos que apresentam maior número delas. Deve-se recorrer a meios suplementares e a métodos pedagógicos especiais a favor de públicos-alvo e de estabelecimentos situados em zonas urbanas ou suburbanas desfavorecidas (DELORS, 1998, p. 24, 146-147).

\subsection{Morin e os saberes necessários à educação do futuro}

Da UNESCO também partiu a ideia, em 1999, de encomendar ao filósofo francês Edgar Morin a exposição das suas ideias sobre a educação do amanhã, com o objetivo, dentre outros, de aprofundar a visão transdisciplinar da educação.

Informa Edgar Morin que seu texto não é um tratado sobre o conjunto das disciplinas que são ou deveriam ser ensinadas. Sua intenção foi, única e essencialmente, expor problemas centrais ou fundamentais que permanecem totalmente ignorados ou esquecidos e que são necessários para se ensinar.

Para o filósofo, há sete saberes fundamentais que a educação do futuro deveria tratar em toda sociedade e em toda cultura, sem exclusividade nem rejeição, segundo modelos e regras próprias a cada sociedade e a cada cultura. Eis os sete saberes necessários à educação do futuro:

$1^{\circ}$ ) As cegueiras do conhecimento (o erro e a ilusão): é impressionante que a educação que visa a transmitir conhecimentos seja cega quanto ao que é o conhecimento humano, seus RELEDUC | ISE | v. 3 | n. 1 | dez. 2020 
dispositivos, enfermidades, dificuldades, tendências ao erro e à ilusão, e não se preocupe em fazer conhecer o que é conhecer. Assim, mister o estudo das características cerebrais, mentais, culturais dos conhecimentos humanos, de seus processos e modalidades, das disposições tanto psíquicas quanto culturais que o conduzem ao erro ou à ilusão (MORIN, 2000, p. 13-14, 19-33).

$2^{\circ}$ ) Os princípios do conhecimento pertinente: a supremacia do conhecimento fragmentado de acordo com as disciplinas impede frequentemente de operar o vínculo entre as partes e a totalidade, e deve ser substituída por um modo de conhecimento capaz de apreender os objetos em seu contexto, sua complexidade, seu conjunto. Deste modo, é necessário desenvolver a aptidão natural do espírito humano para situar todas essas informações em um contexto e um conjunto. É preciso ensinar os métodos que permitam estabelecer as relações mútuas e as influências recíprocas entre as partes e o todo em um mundo complexo (MORIN, 2000, p. 14$15,35-46)$.

$3^{\circ}$ ) Ensinar a condição humana: o ser humano é a um só tempo físico, biológico, psíquico, cultural, social, histórico. Esta unidade complexa da natureza humana é totalmente desintegrada na educação por meio das disciplinas, tendo-se tornado impossível aprender o que significa ser humano. É preciso restaurá-la, de modo que cada um, onde quer que se encontre, tome conhecimento e consciência, ao mesmo tempo, de sua identidade complexa e de sua identidade comum a todos os outros humanos. Desse modo, a condição humana deveria ser o objeto essencial de todo o ensino (MORIN, 2000, p. 15, 47-61).

$4^{\circ}$ ) Ensinar a identidade terrena: o destino planetário do gênero humano é outra realidade chave até agora ignorada pela educação. O conhecimento dos desenvolvimentos da era planetária, que tendem a crescer no século XXI, e o reconhecimento da identidade terrena, que se tornará cada vez mais indispensável a cada um e a todos, devem converter-se em um dos principais objetos da educação. Convém ensinar a história da era planetária, que se inicia com o estabelecimento da comunicação entre todos os continentes no século XVI, e mostrar como todas as partes do mundo se tornaram solidárias, sem, contudo, ocultar as opressões e a dominação que devastaram a humanidade e que ainda não desapareceram. Será preciso indicar o complexo de crise planetária que marca o século $\mathrm{XX}$, mostrando que todos os seres humanos, confrontados de agora em diante aos mesmos problemas de vida e de morte, partilham um destino comum (MORIN, 2000, p. 15-16, 63-78).

$5^{\circ}$ ) Enfrentar as incertezas: as ciências permitiram a aquisição de muitas certezas, mas igualmente revelaram, ao longo do século XX, inúmeras zonas de incerteza. A educação deveria incluir o ensino das incertezas que surgiram nas ciências físicas (microfísicas, termodinâmica, RELEDUC | ISE $|\stackrel{7}{7} .3|$ n. 1 | dez. 2020 
cosmologia), nas ciências da evolução biológica e nas ciências históricas. Seria preciso ensinar princípios de estratégia que permitiriam enfrentar os imprevistos, o inesperado e a incerteza, e modificar seu desenvolvimento, em virtude das informações adquiridas ao longo do tempo. É preciso aprender a navegar em um oceano de incertezas em meio a arquipélagos de certeza. $\mathrm{O}$ abandono das concepções deterministas da história humana que acreditavam poder predizer nosso futuro, o estudo dos grandes acontecimentos e desastres de nosso século, todos inesperados, o caráter doravante desconhecido da aventura humana devem-nos incitar a preparar as mentes para esperar o inesperado, para enfrentá-lo. É necessário que todos os que se ocupam da educação constituam a vanguarda ante a incerteza de nossos tempos (MORIN, 2000, p. 16, 79-92).

$6^{\circ}$ ) Ensinar a compreensão: a compreensão é a um só tempo meio e fim da comunicação humana. Entretanto, a educação para a compreensão está ausente do ensino. O planeta necessita, em todos os sentidos, de compreensão mútua. Considerando a importância da educação para a compreensão, em todos os níveis educativos e em todas as idades, o desenvolvimento da compreensão pede a reforma das mentalidades. Esta deve ser a obra para a educação do futuro. A compreensão mútua entre os seres humanos, quer próximos, quer estranhos, é daqui para a frente vital para que as relações humanas saiam de seu estado bárbaro de incompreensão. Daí decorre a necessidade de estudar a incompreensão a partir de suas raízes, suas modalidades e seus efeitos. Este estudo é tanto mais necessário porque enfocaria não os sintomas, mas as causas do racismo, da xenofobia, do desprezo. Constituiria, ao mesmo tempo, uma das bases mais seguras da educação para a paz, à qual estamos ligados por essência e vocação (MORIN, 2000, p. 16-17, 93-104).

$7^{\circ}$ ) A ética do gênero humano: a educação deve conduzir à "antropo-ética", levando em conta o caráter ternário da condição humana, que é ser ao mesmo tempo indivíduo/sociedade/espécie. Nesse sentido, a ética indivíduo/espécie necessita do controle mútuo da sociedade pelo indivíduo e do indivíduo pela sociedade, ou seja, a democracia; a ética indivíduo/espécie convoca, ao século XXI, a cidadania terrestre. A ética não poderia ser ensinada por meio de lições de moral. Deve formar-se nas mentes com base na consciência de que o humano é, ao mesmo tempo, indivíduo, parte da sociedade, parte da espécie. Carregamos em nós esta tripla realidade. Desse modo, todo desenvolvimento verdadeiramente humano deve compreender o desenvolvimento conjunto das autonomias individuais, das participações comunitárias e da consciência de pertencer à espécie humana. Partindo disso, esboçam-se duas grandes finalidades ético-políticas do novo milênio: estabelecer uma relação de controle mútuo 8

RELEDUC | ISE | v. 3 | n. 1 | dez. 2020 
entre a sociedade e os indivíduos pela democracia e conceber a Humanidade como comunidade planetária. A educação deve contribuir não somente para a tomada de consciência de nossa Terra-Pátria, mas também permitir que esta consciência se traduza em vontade de realizar a cidadania terrena (MORIN, 2000, p. 17-18, 105-115).

As considerações de Edgar Morin consistem certamente numa provocação a todos os educadores interessados em estudar e repensar os objetivos das instituições de ensino de todos os níveis e modalidades de educação. Do mesmo modo, suas reflexões se contrapõem indiretamente aos que defendem que o ensino superior se destina exclusivamente à formação de pessoal para o mercado de trabalho e se esquecem que um curso superior influi expressivamente na vida dos indivíduos e nos destinos da sociedade.

Em outras palavras,

\begin{abstract}
a educação serve à sociedade de diversas maneiras e sua meta é formar pessoas mais sábias, possuidoras de mais conhecimentos, bem informadas, éticas, responsáveis, críticas e capazes de continuar aprendendo. Se todos os seres humanos tivessem essas aptidões e qualidades, os problemas do mundo não se resolveriam automaticamente, porém os meios e a vontade de fazê-lo estariam ao alcance das mãos. A educação também serve à sociedade, oferecendo uma visão crítica do mundo, especialmente de suas deficiências e injustiças e promovendo maior grau de consciência e sensibilidade, explorando novas visões e conceitos e inventando novas técnicas e instrumentos. A educação é, também, o meio de divulgar o conhecimento e desenvolver talentos para introduzir as mudanças desejadas nas condutas, valores e estilos de vida e para suscitar o apoio público às mudanças contínuas e fundamentais que serão imprescindíveis para que a humanidade possa modificar sua trajetória, abandonando a via mais comum que leva a dificuldades cada vez maiores e a uma possível catástrofe, para iniciar seu caminho a um futuro sustentável. A educação é, em síntese, a melhor esperança e o meio mais eficaz que a humanidade tem para alcançar o desenvolvimento sustentável. (UNESCO, 1999, p. 35)
\end{abstract}

A educação superior, materializada nas práticas de suas instituições, do ponto de vista de sua função social e pública, isto é, da perspectiva daquilo que política e filosoficamente lhe justifica a existência, existe para expandir os processos civilizatórios, desenvolver e aprofundar os interesses sociais e públicos que se hegemonizam em uma dada situação das disputas sociais e das relações de poder. Do ponto de vista ideal, mas sem desconsiderar as reais contradições e limites de qualquer fenômeno humano e social, uma instituição de educação superior existe para cumprir o mandato social de produzir os conhecimentos emancipatórios, formar os cidadãos e assim desenvolver a sociedade humana, segundo e mediante os valores e princípios mais caros ao processo civilizatório e à vida democrática, tais como a solidariedade, a cooperação, a justiça, a igualdade, o direito à dignidade, o respeito à alteridade e à pluralidade. É preciso insistir na ideia de que a razão de ser da educação, o que lhe fornece os fundamentos e os objetivos essenciais, é a formação global dos cidadãos, sendo dever da instituição de educação superior 
construir-se cada vez mais intensa e extensamente como um espaço público, que é o espaço da democracia, que não pode ser confundido com o mercado, pois os objetivos de uma e de outro não são os mesmos. A grande tarefa da universidade é, pois, a construção de um espaço público cujos valores falem mais alto e sejam mais duradouros que os interesses utilitaristas e de curto prazo do mercado (DIAS SOBRINHO, 2003, p. 109-120).

\subsection{A Declaração Mundial sobre Educação Superior no Século XXI}

Um debate sobre a função do ensino superior não pode deixar de lembrar da Conferência Mundial sobre Educação Superior, convocada pela UNESCO e realizada em sua sede em Paris, de 5 a 9 de outubro de 1998. Desta reunião resultou o documento que reflete a posição oficial da UNESCO e de seus Estados-Membros, denominado de Declaração Mundial sobre Educação Superior no Século XXI: Visão e Ação (UNESCO, 1998).

O texto da referida Declaração também transparece que a educação superior tem um objetivo muito maior do que simplesmente formar profissionais para o mercado de trabalho. Estatui o documento, em seu artigo $1^{\circ}$, que as missões e valores fundamentais da educação superior, em particular a missão de contribuir para o desenvolvimento sustentável e o melhoramento da sociedade como um todo, devem ser preservados, reforçados e expandidos ainda mais.

Definindo orientações de longo prazo baseadas na relevância da educação superior, a Declaração estabelece que a preocupação do ensino superior deve ser a de facilitar o acesso a uma educação geral ampla, especializada e frequentemente interdisciplinar para determinadas áreas, focalizando-se as habilidades e aptidões que preparem os indivíduos tanto para viver em uma diversidade de situações como para poder reorientar suas atividades. Dispõe, ainda, que a educação superior deve reforçar o seu papel de serviço extensivo à sociedade, especialmente as atividades voltadas para a eliminação da pobreza, intolerância, violência, analfabetismo, fome, deterioração do meio-ambiente e enfermidades, principalmente por meio de uma perspectiva interdisciplinar e transdisciplinar para a análise dos problemas e questões levantadas $\left(\operatorname{art.~} 6^{\circ}\right.$ ).

\subsection{A Constituição Federal do Brasil}

Para dar sequência ao estudo, altera-se o eixo de análise para as normas fixadas no Brasil, recortando-se o tema para averiguar a Constituição brasileira. 
Desse modo, salienta-se que a Constituição Federal do Brasil, embora trate do ensino superior, não dispõe expressamente sobre a função específica que o mesmo deva desempenhar. Mister, então, fazer referência aos objetivos do país e da educação como um todo, estabelecidos pela Carta Magna nos artigos $3^{\circ}$ e 205 , respectivamente.

$\mathrm{O}$ artigo $3^{\circ}$ prescreve que constituem objetivos fundamentais da República Federativa do Brasil, dentre outros, construir uma sociedade livre, justa e solidária; garantir o desenvolvimento nacional; erradicar a pobreza e a marginalização e reduzir as desigualdades sociais e regionais; promover o bem de todos, sem preconceitos de origem, raça, sexo, cor, idade e quaisquer outras formas de discriminação.

Salta aos olhos que os objetivos da República Federativa do Brasil estão ligados à ideia de Justiça. Neste ponto, convém ressaltar que a justiça social se assemelha à "justiça prática" estudada por Serge-Christophe Kolm, segundo o qual consiste em "cuidar primeiro das pessoas mais miseráveis". Para ele, "o princípio da Justiça Prática deve ser examinado com referência a seu significado nas aplicações práticas" e tem relação direta com a "questão das necessidades". Explana que "em uma sociedade na qual as necessidades básicas não são satisfeitas, a Justiça Prática equivale a dar prioridade à sua satisfação" (KOLM, 2000, p. 198-199).

Considerando o sentido de justiça aferido neste estudo, importa evidenciar, utilizando-se da expressão de Luiz Alberto Warat, a possibilidade e até mesmo necessidade de "utopias eficientes", assim definidas porque convocam esperanças e esforços de transformação, estimulam os que foram socialmente excluídos da vida para reivindicar, por eles mesmos, os caminhos da autonomia e porque podem servir, para estes excluídos, a descobrir o que neles foi silenciado pelas repressões máximas da cultura (WARAT, 1994, p. 23).

Estes objetivos, estabelecidos pela Lei Maior brasileira, se constituem também em metas a serem alcançadas pela educação, inclusive pelo ensino superior e pelas instituições que o oferecem. Destarte, uma instituição de ensino superior de qualquer país, ao possibilitar que pessoas se formem e recebam um diploma, está certamente contribuindo para uma sociedade mais livre, justa e solidária, está ajudando no desenvolvimento do país, está contribuindo para a erradicação da pobreza e da marginalização, está diminuindo as desigualdades sociais e, ainda, está promovendo o bem-estar de todos.

Tratando especificamente da educação, o artigo 205 da Carta Magna brasileira atesta que ela, "direito de todos e dever do Estado e da família, será promovida e incentivada com a colaboração da sociedade, visando ao pleno desenvolvimento da pessoa, seu preparo para o exercício da cidadania e sua qualificação para o trabalho". 
Constata-se, assim, que são objetivos da educação no Brasil contribuir para o pleno desenvolvimento da pessoa, prepará-la para o exercício da cidadania e qualificá-la para o trabalho. Vê-se que cidadania, desenvolvimento e trabalho são fatores primordiais que devem ser lembrados e almejados pela educação. Em outras palavras, a educação, segundo a Constituição brasileira, deve buscar incutir na pessoa: a) o aprender a conhecer (desenvolvimento humano), pois cada vez é mais inútil tentar conhecer tudo e o processo de aprendizagem jamais se acaba; b) o aprender a viver juntos (exercício da cidadania), para participar e cooperar com os outros em todas as atividades humanas, desenvolvendo a compreensão do outro e a percepção das interdependências; e c) o aprender a fazer (qualificação para o trabalho), para assim poder agir sobre o meio envolvente, objetivando adquirir não somente uma qualificação profissional, mas, de uma maneira mais ampla, competências que tornem a pessoa apta a enfrentar numerosas situações e a trabalhar em equipe. A soma destes três pilares da educação, nas palavras do Relatório Delors, implica no aprender a ser, para melhor desenvolver a personalidade e estar à altura de agir com cada vez maior capacidade de autonomia, de discernimento e de responsabilidade pessoal.

Impõe salientar, outrossim, que a atual Carta Magna brasileira elevou a dignidade da pessoa humana a princípio fundamental da República Federativa do Brasil (art. $1^{\circ}$, III).

Evidente, pois, que tal princípio deve nortear a leitura e interpretação de toda e qualquer norma, inclusive aquelas relacionadas à educação, até mesmo as próprias disposições constitucionais. Assim, se a dignidade da pessoa humana é fundamento e/ou objetivo de um país, deve esta dignidade ser buscada incessantemente por todos (Estados, sociedade, família, instituições, organizações etc.) e um dos modos de se alcançá-la é através da educação, que também tem como meta contribuir para a preservação e, em alguns casos, recuperação da dignidade da pessoa humana.

Ingo Wolfgang Sarlet conceitua a dignidade da pessoa humana como a

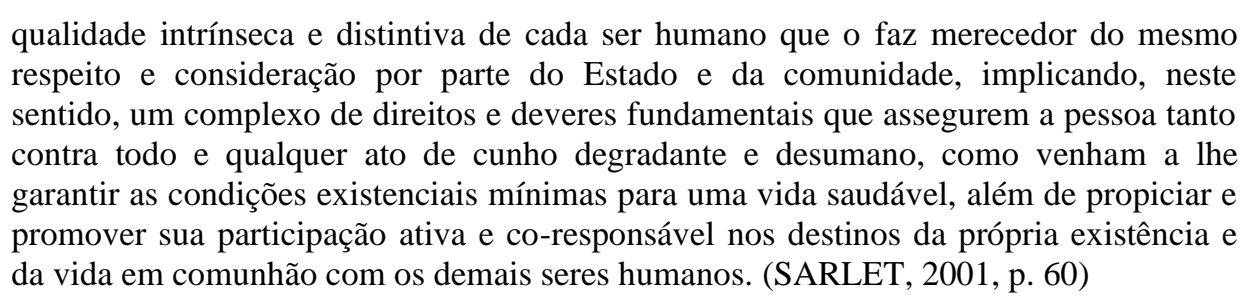

Inexistirá a dignidade da pessoa humana, por exemplo, onde não houver respeito pela integridade física e moral do ser humano, onde não se reverenciar sua liberdade, onde não se reconhecer os direitos fundamentais, a autonomia, a igualdade, e onde não se encontrar as 
mínimas condições para uma existência digna.

Enfim, pode-se assegurar que a Constituição Federal brasileira em vigor elegeu o valor da dignidade humana como um valor essencial que lhe dá unidade de sentido, ou seja, o valor da dignidade humana informa a ordem constitucional de 1988, imprimindo-lhe uma feição particular (PIOVESAN, 1997, p. 59).

Este sucinto excurso sobre um dos fundamentos da República Federativa do Brasil, repita-se, demonstra que a educação também tem como meta contribuir para a preservação e, em alguns casos, recuperação da dignidade da pessoa humana. E efetivamente um curso superior colabora para que isso ocorra.

\section{TEORIA E PRÁTICA NAS SALAS DE AULA}

Dentre muitas definições que se apresentam, pode-se afirmar, muito singelamente, que teoria é o conjunto de princípios, de regras, de leis científicas, de conceitos que descrevem e explicam um certo conjunto de fatos, que fundamentam uma atividade, uma arte, e que lhe determinam a prática. Por outro lado, prática diz respeito à ação, à aplicação de regras ou princípios de uma ciência ou de uma arte. Praticar é realizar, aplicar regras teóricas, exercitar.

Os significados das palavras teoria e prática demonstram que uma não sobrevive sem a outra. De nada adiantará a um aluno conhecer profundamente a teoria se não souber aplicá-la. Do mesmo modo, será inútil ter ciência dos procedimentos práticos para a realização de algo se não se tem domínio sobre este algo.

Não seria equivocado dizer, então, diante do acima exposto, que a teoria e a prática estão bastante próximas, tanto que uma depende da outra. Partindo dessa premissa, tem-se que tal proximidade facilita a articulação da teoria com a prática, notadamente se o professor tiver conhecimento de ambas, ressaltando que não se faz necessário que o professor exerça a prática, mas sim que dela tenha pleno conhecimento.

Mas o que se pretende com este trabalho é também discutir a metodologia do ensino, abordando especificamente o debate de como trabalhar a teoria com a prática, razão pela qual passa-se a expor, também num condensado espaço, um dos modos de atuação de um professor numa sala de aula de um curso superior.

Assevera-se, de início, que não se pode lecionar nenhuma matéria, seja ela oriunda de qualquer disciplina, sem adotar como ponto de partida a realidade do aluno. Não deve o 
professor iniciar sua aula com a exposição da teoria e, depois, tentar demonstrar sua aplicação prática com exemplos. A inversão desse procedimento é medida que se impõe.

Extrair do aluno fatos que fazem parte do seu dia-a-dia, relacionando-os com a matéria que será em seguida ministrada/debatida, demonstrará para o discente que aquilo que o professor tenta lhe ensinar não é algo tão novo assim, mas, ao contrário, é tema que está intimamente ligado ao seu cotidiano. Num momento posterior, enriqueceria o docente sua aula com a explanação de casos práticos relacionados com o conteúdo, procurando dar preferência para exemplos que tenham ligação direta com as ideias apresentadas pelos próprios alunos.

Como se vê, condena-se as formas tradicionais de se ministrar aulas, dentre as quais se pode citar como as mais utilizadas aquelas exclusivamente expositivas e aquelas em que o docente adentra à sala, explica a teoria e dá exemplos, permitindo pouca participação do discente. Em outros termos, crucifica-se a tradicional educação bancária, que ainda é levada a efeito por muitos docentes, e privilegia-se a educação conscientizadora. Para não alongar este trabalho, evita-se adentrar minuciosamente neste tema, razão pela qual seguem adiante, discriminadas num quadro, as principais diferenças entre estas duas formas de educação, levando-se em consideração cinco pontos importantes em qualquer processo de aprendizagem:

\begin{tabular}{|l|l|l|}
\cline { 2 - 3 } \multicolumn{1}{c|}{} & \multicolumn{1}{c|}{ Educação Bancária } & \multicolumn{1}{c|}{ Educação Conscientizadora } \\
\hline 1) Objetivos & $\begin{array}{l}\text { - transmitir conhecimento; dar } \\
\text { continuidade a cultura; educação } \\
\text { conservadora. }\end{array}$ & $\begin{array}{l}\text { - produzir conhecimento; construir } \\
\text { conhecimento; consciência crítica; } \\
\text { relacionar teoria e prática, ação e } \\
\text { reflexão. }\end{array}$ \\
\hline 2) Conteúdo & $\begin{array}{l}\text { - reprodução de informações de } \\
\text { forma compartimentada, abstrata. }\end{array}$ & $\begin{array}{l}\text { - problemas concretos, } \\
\text { significativos para os alunos. }\end{array}$ \\
\hline 3) Métodos & $\begin{array}{l}\text { - aula expositiva, apresentação } \\
\text { oral, narração, preleção. }\end{array}$ & $\begin{array}{l}\text { - diálogo, discussão, debate, } \\
\text { trabalho em grupo. }\end{array}$ \\
\hline 4) Avaliação & $\begin{array}{l}\text { - cobrança daquilo que foi } \\
\text { depositado no aluno, através de } \\
\text { provas e exames. }\end{array}$ & $\begin{array}{l}\text { solução de problemas, também } \\
\text { através de provas, exames (alguns } \\
\text { com consulta) e, ainda, através da } \\
\text { autoavaliação. }\end{array}$ \\
\hline $\begin{array}{l}\text { 5) Relação } \\
\text { professor/aluno }\end{array}$ & $\begin{array}{l}\text { - vertical, baseada na autoridade do } \\
\text { professor. }\end{array}$ & $\begin{array}{l}\text { - horizontal, através de uma relação } \\
\text { interpessoal, entre iguais, com } \\
\text { troca de experiências. }\end{array}$ \\
\hline
\end{tabular}

Tais expressões (educação bancária e educação conscientizadora), como cediço, foram utilizadas por Paulo Freire (1987, passim; 1996, passim), mas existem diversas outras que possuem o mesmo significado e alcance. É o que ocorre, por exemplo, com "pedagogia da caçamba", "ensino almoxarifado" e "educação depósito", que expressam o mesmo sentido de 
educação bancária. Na mesma linha de educação conscientizadora, pode-se adotar "ensino problematizante", "pedagogia da consciência" e "ensino da autonomia".

Sugere-se, destarte, almejando melhorar a didática e tornar eficiente a articulação da teoria com a prática, que o professor instigue o aluno a apresentar sua realidade, que a tome como ponto de partida, que desta caminhe para o desenvolvimento do conteúdo, progredindo de maneira clara e simples a teoria, até, enfim, retornar e atingir novamente o cotidiano do discente. É o que se tenta demonstrar através do esquema abaixo (CASAGRANDE, 2000):

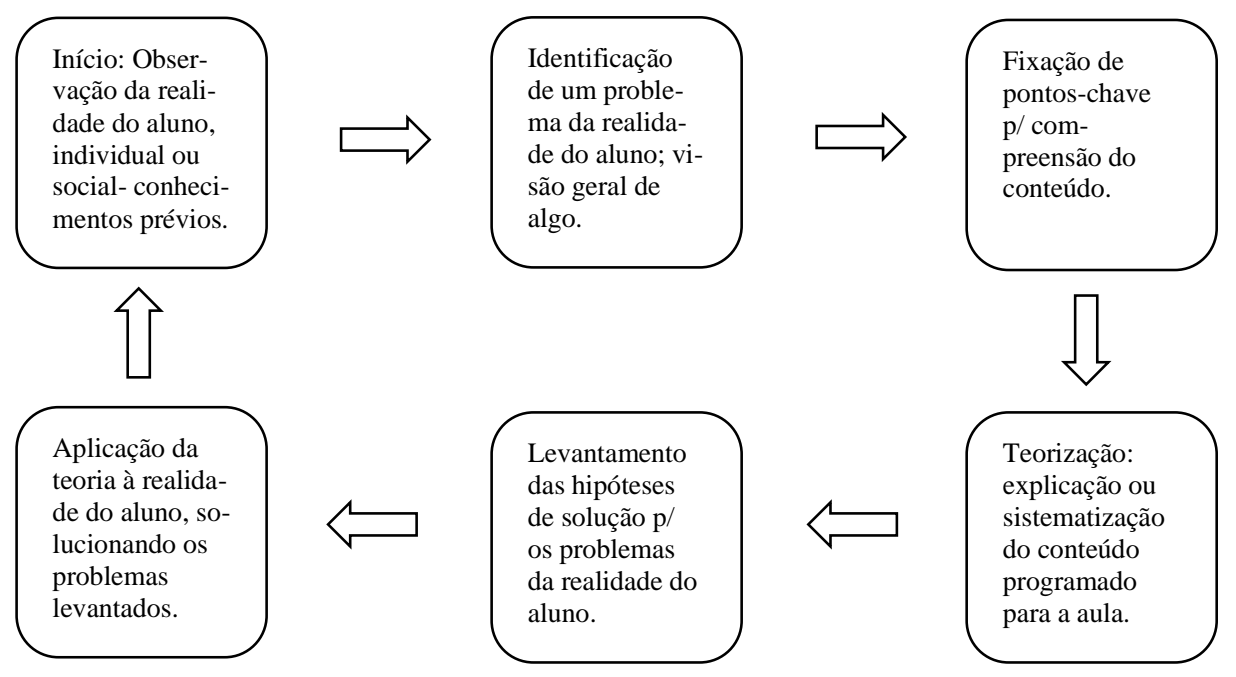

A questão que surge agora é como trabalhar com os alunos da maneira acima exposta ou, em outras palavras, que método e quais técnicas de ensino utilizar em sala de aula, de modo a despertar no discente a vontade de aprender.

\section{MÉTODO DE PROBLEMAS}

Ao invés de classificar um modo de atuar em sala de aula em uma das estratégias de aprendizagem ou metodologias tradicionais, prefere-se apresentar uma distinção singela entre método e técnica de ensino. Não se repele as outras classificações, apenas se propõe uma visão mais simples, que é a intenção primeira deste trabalho.

Um método de ensino é formado por aquele aglomerado de procedimentos que vai desde a apresentação do conteúdo até a verificação da aprendizagem. Por outro lado, técnica de ensino, ou estratégia, é o procedimento didático que serve para colaborar na realização de uma parte da aprendizagem a que se propõe o método. Desse modo, apenas um método de ensino pode se utilizar, durante sua aplicação, de um número variado de técnicas. 
O método de problemas (ou método de solução de problemas) considera que faz parte da arte de ensinar a apresentação de problemas e que, por outro lado, faz parte da arte de aprender solucionar os problemas apresentados.

Assim, tal método consiste em propor situações problemáticas aos alunos, os quais, para solucioná-las, terão que realizar pesquisas ou revisar e reestudar o conteúdo. Coloca-se uma situação-problema ao discente, desafiando-o a encontrar uma solução satisfatória para a mesma.

Não se faz necessário que o problema advenha de uma situação real. Todavia, é indispensável que o problema incomode o aluno. Com efeito, a solução da situação nunca será imprescindível para o aluno se o problema não for insuportável. O educando tem que sentir necessidade de resolver o problema.

Dentre as inúmeras vantagens de se fazer uso do método de problemas estão a maior facilidade de articulação da teoria com a prática em sala de aula e a criação no aluno de uma consciência crítica e de uma autonomia científica indispensáveis ao seu futuro profissional.

Um método de ensino somente será eficaz se não apresentar muita informação aos alunos; e é assim que ocorre com o método de problemas, que é realmente bom porque trabalha com a curiosidade dos alunos. Não objetiva formar memorizadores da matéria, mas sim discentes curiosos, futuros pesquisadores. Quanto mais teoria for colocada aos alunos, menor será sua capacidade de pesquisa e maior a chance de se estar formando eruditos sem capacidade crítica. É preciso criar no aluno a vontade de virar a página do livro, de se dedicar mais a um assunto, de querer ler mais sobre algo, afastando dele a ideia, às vezes inconsciente, de que o livro que está lendo é o último ou o único sobre determinada matéria. O ensino fundamentado na solução de problemas gera nos alunos habilidades que os tornam capazes de desenvolver com êxito a autoaprendizagem, qualidade indispensável no exercício de qualquer profissão.

\section{TÉCNICAS RELACIONADAS AO MÉTODO DE PROBLEMAS}

É possível afirmar que são quatro as técnicas de ensino que podem fazer parte do conjunto de ações do método de problemas: a técnica atenuada de problemas, a técnica integral de problemas, a técnica integrada de problemas e a técnica de casos.

$\mathrm{Na}$ técnica atenuada de problemas o professor apresenta aos alunos o conteúdo programado da maneira que julgar melhor (aula expositiva ou dialogada, estudo dirigido etc.) e, quando entender que os educandos assimilaram o conteúdo ou que ao menos já deveriam ter assimilado, coloca-os diante de uma situação relacionada com o conteúdo apresentado. Para

$$
\text { RELEDUC | ISE | v. } 3 \text { | n. } 1 \text { | dez. } 2020
$$


resolverem o problema, os alunos terão que revisar ou reestudar o conteúdo que lhes foi apresentado, o que pode ser feito individualmente ou em grupo. Em seguida, os discentes apresentam as soluções ou sugestões de soluções para a situação, todas devidamente fundamentadas, as quais devem ser aceitas ou repelidas pelo professor, que também deve fundamentar seus comentários, fazendo-o perante todos os alunos.

A diferença entre a técnica atenuada de problemas e a técnica integral de problemas é que, nesta, primeiro se apresenta a situação ao aluno, antes mesmo da apresentação do conteúdo. Coloca-se, então, o discente diante de uma situação problemática, demonstrando para ele os caminhos que devem ser percorridos para a solução, sendo indispensável, pois, a indicação da legislação aplicável e da bibliografia que deverá ser consultada. Antes da colocação da situação, faz-se mister demonstrar a importância do conteúdo envolvido no problema, sem que haja a apresentação propriamente dita. Posteriormente, aplica-se o que restou dito acima quanto a técnica atenuada.

A técnica integrada de problemas é assim chamada porque para a solução do problema se faz necessário o estudo, a pesquisa ou a revisão do conteúdo de duas ou mais disciplinas, podendo envolver dois ou mais professores. Para a aplicação desta técnica devem ser seguidos os procedimentos de uma das técnicas acima apresentadas.

Por fim, a técnica de casos distingue-se das demais técnicas unicamente pelo fato de que nesta os problemas apresentados aos alunos são reais, ou ao menos análogos aos reais, e já foram submetidos à apreciação de um julgador (juiz, tribunal, árbitro, conselho etc.), que deu seu veredicto, isto é, uma solução para o problema.

Alguém poderia levantar empecilhos para se aplicar tais técnicas nos dias de hoje, ainda mais considerando que alguns alunos possuem dificuldades enormes de interpretação de texto, de utilização da gramática e de elaboração de frases lógicas, fatores estes comumente divulgados por docentes nos corredores e nas salas de professores. Certamente eu responderia que prefiro acreditar na capacidade do aluno e que esta não foi até o momento instigada, do que rebaixar a aula ao menor nível possível e desacreditar os alunos de que podem ser melhores.

\section{PROCEDIMENTOS PARALELOS}

De nada adiantará somente utilizar ou aplicar as técnicas apresentadas se não forem observados outros pontos imprescindíveis. Aliás, ressalta-se desde já que os pontos a seguir tratados são indispensáveis seja qual for o método de aula utilizado.

$$
\text { RELEDUC | ISE | v. } 3 \text { | n. } 1 \text { | dez. } 2020
$$


Inicialmente, salienta-se a necessidade de o professor elaborar e apresentar aos alunos, no primeiro dia de aula, ou antes, um plano de ensino da sua disciplina que seja realmente esclarecedor e que aborde necessariamente os objetivos gerais e específicos da mesma, a ementa, o conteúdo programático, a previsão minuciosa das datas em que serão debatidas as matérias (cronograma das aulas), as estratégias e a metodologia de ensino, as formas de avaliação, a bibliografia básica e a bibliografia complementar.

Além do plano de ensino, mister se faz a elaboração e o envio aos discentes, com razoável antecedência (pelo menos uma semana), de informações a respeito da matéria que será debatida em sala de aula, com sua precisa identificação, textos doutrinários resumidos, legislação, indicação de bibliografia básica e complementar, decisões judiciais importantes que tenham relação com o conteúdo etc.. Este documento, que pode ser denominado de plano de aula, não deve ser extenso e nem conter muitas informações, ou seja, jamais deve esgotar o assunto, pois permitiria ao aluno estudar apenas por ele, deixando de lado obras doutrinárias, o que dificultaria ou desestimularia a pesquisa e o auto aprendizado.

Tal procedimento obriga o professor a preparar com antecedência suas aulas, sendo que hodiernamente inexistem grandes dificuldades para o envio do respectivo material, que pode ser feito via e-mail, cujos endereços podem ser informados pelos discentes no primeiro dia de aula, ou, então, pela tradicional forma de disponibilização em bancas de xerocópias, ou, ainda, em salas virtuais.

Evidente que assim agindo estará o docente proporcionando ao aluno a possibilidade de o mesmo se preparar melhor para a aula. Não se pretende e nem se espera, por óbvio, que todos os discentes atuem dessa maneira. Mas é fato que a aula já será melhor se apenas um deles o fizer, pois com este procedimento o professor estará dando maior oportunidade de manifestação por parte do aluno, o que certamente implicará numa aula mais rica em exemplos e questões práticas originárias do cotidiano do próprio discente e, pois, do dia-a-dia dos seus colegas de classe, fato que também facilitará a articulação da teoria com a prática em sala de aula.

A sugestão que se faz cobra do professor que leve para a sala de aula um conhecimento muito maior do que o de costume. Com efeito, há sim alunos que chegam a sentar nas carteiras com duas, três ou quatro obras doutrinárias relacionadas à matéria que será discutida pelo docente, o que implica na apresentação de questões que efetivamente dizem respeito ao tema proposto, mas que podem exigir do docente muito mais do que ele está acostumado ou, ao menos, muito mais do que uma simples e prévia leitura de um texto qualquer durante a 
preparação da aula. De qualquer maneira, nenhuma aula deve ser improvisada. O professor tem que prepará-la com razoável antecedência.

Outro ponto nevrálgico é o do relacionamento professor-aluno. De nada adiantará agir da maneira como se aconselha se o docente não der ampla liberdade de manifestação ao aluno em sala de aula. Vale evidenciar que se está dizendo "ampla" liberdade, e não irrestrita, pois, como cediço, as colocações do aluno devem pautar pela oportunidade, conveniência e coerência.

De um modo ou de outro, exige-se no processo de aprendizagem um excelente relacionamento entre aluno e docente, o qual, sem sombra de dúvidas, deve ultrapassar os limites do ambiente de uma classe de aula, até o ponto de retirar do discente sua natural inibição e seu normal e tradicional temor do professor, o que lhe facilitará uma participação mais ativa durante as aulas.

Dentre muitos outros comportamentos do docente, arrisca-se a enumerar alguns, apenas a título de sugestão, que podem contribuir para um bom relacionamento aluno/professor: a) evitar que apenas alguns discentes monopolizem a discussão, excluindo os demais; b) estimular momentos em sala nos quais o aluno se sinta livre para expressar sentimentos e opiniões; c) utilizar em suas aulas um vocabulário de fácil compreensão pelo aluno; d) respeitar e exigir respeito às opiniões do aluno, desde que bem fundamentadas, independentemente de divergência doutrinária ou jurisprudencial; e) estimular no discente a tomada de iniciativa, elogiando expressamente aquele que assim age, bem como aquele que presta auxílio aos colegas; e f) dividir com os alunos a responsabilidade de alcançar soluções para problemas que venham a surgir com o próprio docente, com a instituição ou com os demais colegas de classe (ABREU, 1980, p. 118-120).

Por outro lado, eis alguns exemplos de comportamentos do docente que podem impedir ou dificultar um ambiente favorável à aprendizagem: a) irritar-se metodicamente com interrupções e divagações do aluno e responder com sarcasmo as indagações e colocações com pouca pertinência; b) direcionar sua aula para os alunos que possuem facilidade na disciplina, atribuindo pouca ou nenhuma atenção aos demais; c) utilizar-se de quaisquer meios para adquirir notoriedade entre os discentes e destes obter estima; d) não assumir os próprios equívocos perante os alunos; e) tratar diferente os alunos que lhe agradam e lhe causam boa impressão; f) fazer pouco caso da opinião do aluno; g) fazer ameaças ao aluno, como as de persegui-lo durante o curso e reprová-lo na disciplina; h) advertir exagerada e severamente o discente; e i) evitar contatos ou diálogos com os alunos fora da sala de aula ou somente realizá-los mediante remuneração da instituição de ensino (ABREU, 1980, p. 118-120). 
$\mathrm{O}$ ato pedagógico não pode ser simplesmente um ato de incitação intelectual ao conhecimento, devendo ser também uma forte relação afetiva entre o professor e o aluno (PERRETI apud SNYDERS, 1978, p. 228). Não se nega que os recursos didáticos, os procedimentos de ensino, o conteúdo, as atividades práticas e os exercícios são valiosas fontes de incentivo. Mas, de outra parte, afirma-se que uma das maiores fontes de motivação do discente é a personalidade do professor, realmente capaz de tornar a aprendizagem mais eficaz.

\section{CONSIDERAÇÕES FINAIS}

Diante de todo o exposto, impõe-se afirmar que um curso superior não busca apenas formar profissionais para atuar no mercado de trabalho, não gera somente profissionais desta ou daquela profissão. Resta claro e incontestável que o ensino superior tem diversos outros objetivos além da formação de profissionais, uma vez que sempre proporciona ao estudante um mínimo de desenvolvimento sociocultural e humanístico, além de habilitá-lo para inúmeras outras atividades direcionadas ao aumento de conhecimentos.

A educação é um trunfo indispensável à humanidade na sua construção dos ideais da paz, da liberdade e da justiça social, constituindo-se em um processo permanente de enriquecimento dos conhecimentos, do saber-fazer, mas também e talvez em primeiro lugar, como uma via privilegiada de construção da própria pessoa, das relações entre indivíduos, grupos e nações.

As colocações da UNESCO quanto aos quatro pilares da educação e acerca dos sete saberes fundamentais à educação do futuro, como já dito, consistem certamente numa provocação a todos os educadores interessados em estudar e repensar os objetivos das instituições de ensino de todos os níveis e modalidades de educação. Do mesmo modo, suas reflexões se contrapõem indiretamente aos que defendem que o ensino superior se destina exclusivamente à formação de pessoal para o mercado de trabalho e se esquecem que um curso superior influi expressivamente na vida dos indivíduos e nos destinos da sociedade.

Com efeito, aos cursos superiores não cabe apenas a missão de formar pessoas aptas para o trabalho qualificado, mas também a incumbência de lutar contra a desigualdade social e contribuir para a erradicação da pobreza e da exclusão, sendo de rigor proporcionar a inclusão dos grupos social e economicamente marginalizados.

Não restam dúvidas de que a educação serve à sociedade de inúmeras maneiras e seu objetivo é formar pessoas mais sábias, possuidoras de mais conhecimentos, bem informadas, 
éticas, responsáveis, críticas e capazes de continuar aprendendo e de detectar as deficiências e injustiças do mundo.

Enfim, é fato que um curso superior não forma apenas técnicos; forma pessoas mais cidadãs, mais conscientes de seus direitos e deveres, mais aptas a viver em sociedade, mais propensas ao desenvolvimento pessoal; forma melhores pais, melhores mães, melhores filhos; forma pessoas capazes de solucionar conflitos sem se socorrer de advogados e até mesmo do Poder Judiciário; forma pessoas capazes de pensar e criticar a realidade social; forma pessoas com um mínimo de vontade de mudar pra melhor o mundo em que vivem.

A inserção no mercado de trabalho será uma consequência natural de um ensino superior que priorize os quatro pilares da educação apresentados por Jacques Delors e os sete saberes fundamentais à educação elencados por Edgar Morin, cabendo ao professor envidar esforços para atuar nesse sentido junto aos seus alunos.

Não se pode olvidar que cada professor tem seus próprios métodos, os quais se amoldam ao seu jeito de ser e de pensar. Além do mais, não se inventou até os dias de hoje um método capaz de incutir no aluno tudo aquilo de que ele precisa ter conhecimento.

Todavia, não menos certo é o fato de que deve ser abolido o tradicional método expositivo, prelecional, conferencial, que imputa e exige do discente uma conduta absolutamente passiva.

Incentivar no aluno a consciência crítica é medida que se impõe e uma das melhores maneiras de alcançá-la, como já asseverado, é fazendo com que o discente se depare com situações-problema reais e/ou simuladas, que exijam capacidade de interpretação, análise crítica e resposta conceitualmente fundamentada, trazendo a realidade para o ambiente da sala de aula e permitindo vinculação mais fácil da teoria com a prática.

Estas são as ponderações que se tinha a colocar, objetivando tão somente destacar os objetivos do ensino superior e apresentar uma experiência positiva de como atuar em sala de aula, assim como fomentar o debate a respeito da educação superior, notadamente sobre sua metodologia.

\section{REFERÊNCIAS}

ABREU, Maria Célia Teixeira de. $O$ professor universitário em aula: prática e princípios. São Paulo: Cortez, 1980.

CASAGRANDE, Lisete Diniz Ribas. Metodologia do Ensino do Direito, ago-nov/2000, notas de aula. Programa de Mestrado em Direito, Universidade de Ribeirão Preto. 
DELORS, Jacques (coord.). Educação: um tesouro a descobrir: Relatório para a UNESCO da Comissão Internacional sobre Educação para o Século XXI. Tradução de José Carlos Eufrázio. São Paulo: Cortez Editora. Brasília: UNESCO, 1998.

DIAS SOBRINHO, José. "Avaliação da educação superior - valores republicanos, conhecimento para a emancipação, igualdade de condições e inclusão social”. In: UNESCO. A Universidade na Encruzilhada: Seminário Universidade: por que e como reformar? Brasília: UNESCO, 2003, p. 109-120.

FREIRE, Paulo. Pedagogia do oprimido. 17ª ed. Rio de Janeiro: Paz e Terra, 1987.

Pedagogia da autonomia: saberes necessários à prática educativa. $25^{\mathrm{a}}$ ed. São Paulo: Paz e Terra, 1996.

KOLM, Serge-Christophe. Teorias modernas da justiça. Tradução de Jefferson Luiz Camargo e Luís Carlos Borges. São Paulo: Martins Fontes, 2000.

MORIN, Edgar. Os sete saberes necessários à educação do futuro. Tradução de Catarina Eleonora F. da Silva e Jeanne Sawaya. 2a ed. São Paulo: Cortez Editora. Brasília: UNESCO, 2000.

PIOVESAN, Flávia. Direitos Humanos e o Direito Constitucional Internacional. $3^{\text {a }}$ ed. São Paulo: Max Limonad, 1997.

SARLET, Ingo Wolfgang. Dignidade da Pessoa Humana e Direitos Fundamentais na Constituição Federal de 1988. Porto Alegre: Livraria do Advogado, 2001.

SNYDERS, Georges. Para onde vão as pedagogias não-diretivas? Lisboa: Moraes Editores, 1978.

UNESCO. Declaração Mundial sobre Educação Superior no Século XXI: Visão e Ação. Paris: 5 a 9/10/1998. Documento disponível on-line, em http://www.direitoshumanos.usp.br/index.php/Direito-a-Educa\%C3\%A7\%C3\%A3o/declaracaomundial-sobre-educacao-superior-no-seculo-xxi-visao-e-acao.html, acesso em 12/09/2016.

Educação para um futuro sustentável: uma visão transdisciplinar para ações compartilhadas. Brasília: Ed. IBAMA, 1999.

WARAT, Luiz Alberto. Introdução Geral ao Direito: interpretação da lei - temas para uma reformulação. Porto Alegre: Sérgio Antonio Fabris Editor, 1994. 